Supporting Information for:

\title{
Understanding Beam Induced Electronic Excitations in Materials
}

David B. Lingerfelt, Panchapakesan Ganesh, Jacek Jakowski, and Bobby G. Sumpter

Transition rates with different exchange-correlation functionals:

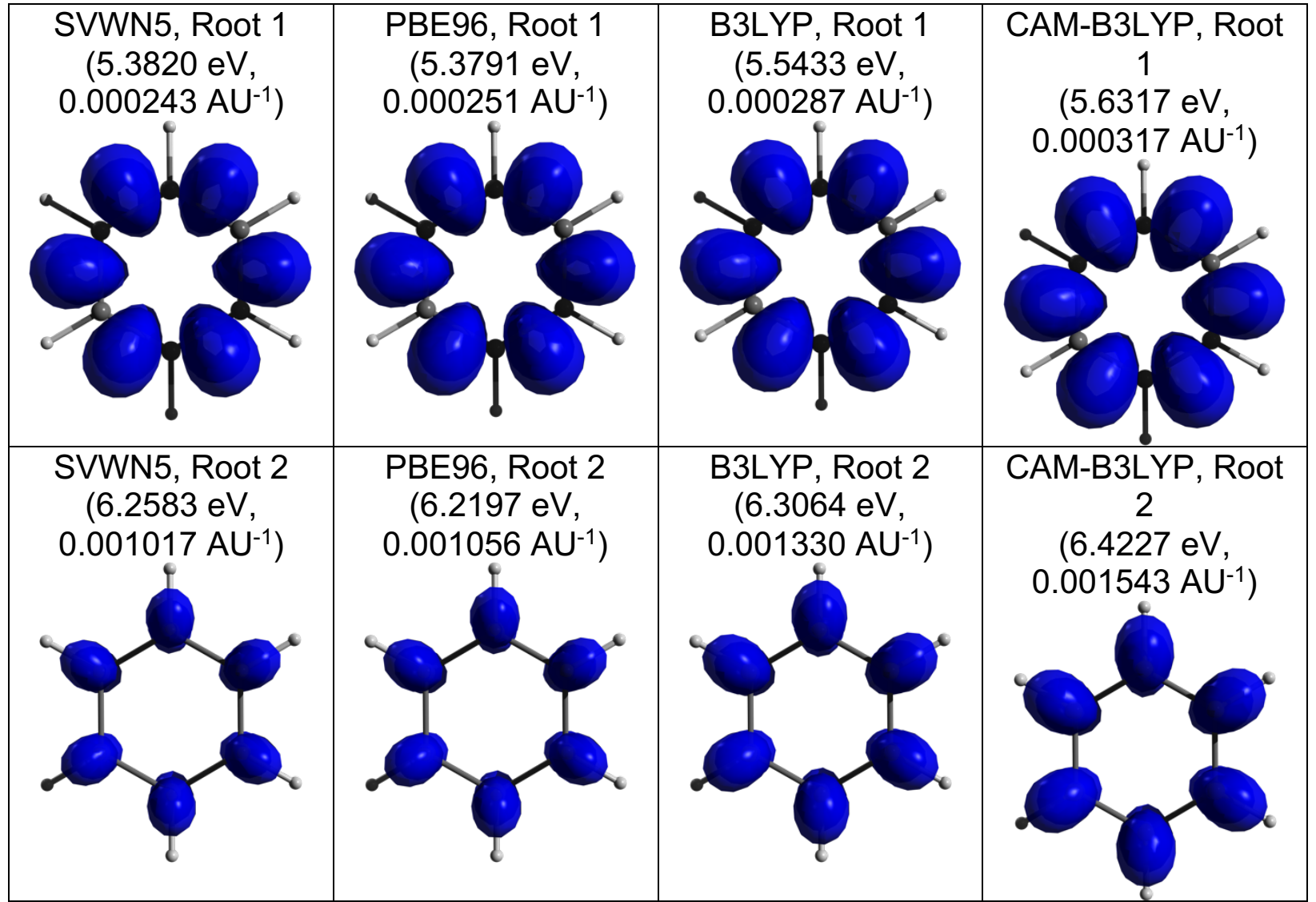

Isosurfaces of the position-dependent transition rate to the two lowest energy excited states of the benzene molecule (B3LYP-optimized geometry used throughout) calculated using an LDA (SVWN5 $\left.{ }^{1,2}\right)$, GGA (PBE96 $\left.{ }^{3,4}\right)$, global hybrid (B3LYP5) and range separated hybrid (CAM-B3LYP ${ }^{6}$ ) functional. The $6-31 \mathrm{~g}(\mathrm{~d})$ basis was employed in each calculation, and the same isovalue $\left(0.001 / 0.01 \mathrm{AU}^{-1}\right.$ for Root $\left.1 / 2\right)$ used to visualize each transition for ease of comparison. Excitation energies and averages of the transition rates evaluated on $6 \times 6 \times 6$ Angstrom grid (0.2 Angstrom gridpoint spacing) are provided (in parenthesis) for each transition in the corresponding panels. 


\begin{tabular}{|c|c|c|}
\hline $\begin{array}{c}\text { Exchange- } \\
\text { correlation } \\
\text { functional }\end{array}$ & $\begin{array}{c}\text { Average } \\
\text { transition rate } \\
\text { to Root 1 } \\
\text { (relative to } \\
\text { SVWN5) }\end{array}$ & $\begin{array}{c}\text { Average } \\
\text { transition rate } \\
\text { to Root 2 } \\
\text { (relative to } \\
\text { SVWN5) }\end{array}$ \\
\hline SVWN5 & $(1)$ & $(1)$ \\
\hline PBE96 & 1.03 & 1.04 \\
\hline B3LYP & 1.18 & 1.31 \\
\hline CAM-B3LYP & 1.30 & 1.52 \\
\hline
\end{tabular}

The average transition rates (at least for this extremely limited comparison) show a trend of increasing magnitude with increasing complexity of the functional (i.e., rates calculated for range separate hybrid > global hybrid > GGA > LDA.). The spatial dependence of the transition rates, however, shows the same character across the field of exchange-correlation functionals surveyed here.

Transition rates with extra polarization functions included in basis:

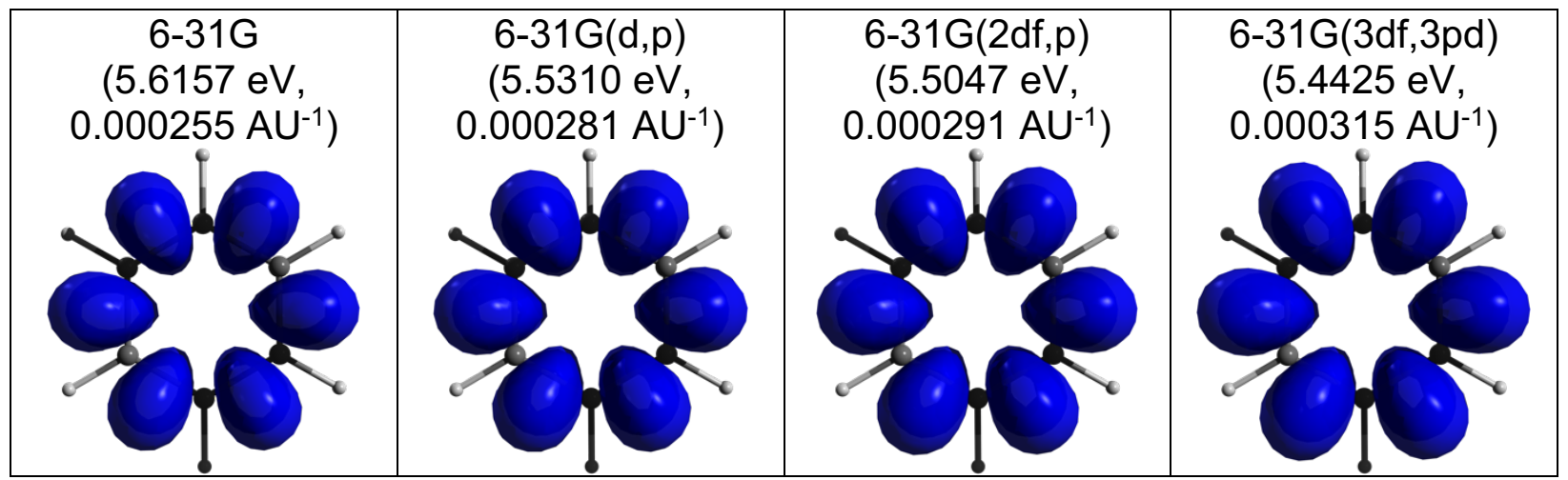

Isosurfaces (isovalue of $0.001 \mathrm{AU}^{-1}$ ) of the position-dependent transition rate to the lowest energy excited state of the benzene molecule. The B3LYP functional was used along with Pople-type $6-31 \mathrm{~g}^{7}$ basis set augmented with different sets of polarization functions. Excitation energies and averages of the transition rates evaluated on $6 \times 6 \times 6$ Angstrom grid (0.2 Angstrom gridpoint spacing) are provided (in parenthesis) for each transition in the corresponding panels.

\begin{tabular}{|c|c|}
\hline Basis Set & $\begin{array}{c}\text { Average } \\
\text { transition rate to } \\
\text { Root 1 (relative } \\
\text { to 6-31G) }\end{array}$ \\
\hline $6-31 \mathrm{G}$ & $(1)$ \\
\hline $6-31 \mathrm{G}(\mathrm{d}, \mathrm{p})$ & 1.10 \\
\hline $6-31 \mathrm{G}(2 \mathrm{df}, \mathrm{p})$ & 1.14 \\
\hline $6-31 \mathrm{G}(3 \mathrm{df}, 3 \mathrm{pd})$ & 1.24 \\
\hline
\end{tabular}


Much like the trend observed with respect to the exchange-correlation functional, the average transition rates see an increase in magnitude for more complete basis sets, while the character of the spatial variation of the rates is essentially preserved.

1. J.C. Slater and K. H. Johnson, Phys. Rev. B 5, 844 (1972)

2. $\quad$ S.J. Vosko, L. Wilk and M. Nusair, Can. J. Phys. 58, 1200 (1980)

3. J.P. Perdew, K. Burke and M. Ernzerhof, Phys. Rev. Lett. 77, 3865 (1996)

4. J.P. Perdew, K. Burke and M. Ernzerhof, Phys. Rev. Lett. 78, 1396 (1997)

5. A.D. Becke, J. Chem. Phys. 98, 5648 (1993)

6. T. Yanai, D. P. Tew and N.C. Handy, Chem. Phys. Lett. 393, 51 (2004)

7. W. J. Hehre, R. Ditchfield, J. A. Pople, J. Chem. Phys. 56, 2257 (1972) 